\title{
Venous Thromboembolism-Incidence of Deep Venous Thrombosis and Pulmonary Embolism in Patients with Head and Neck Cancer: A Tertiary Care Experience in Pakistan
}

\author{
Naeem Sultan Ali ${ }^{1} \quad$ Ahmad Nawaz ${ }^{2}$ Montasir Junaid ${ }^{3} \quad$ Maliha Kazi $^{3}$ Shabbir Akhtar ${ }^{3}$ \\ ${ }^{1}$ Department of Otorhinolaryngology and Head Neck Surgery, The \\ Aga Khan Hospital, Dar Es Salaam, United Republic of Tanzania \\ 2 Department of ENT, Liaquat National Hospital, Karachi, Pakistan \\ ${ }^{3}$ Division of ENT, The Aga Khan University hospital, Karachi, Pakistan \\ Address for correspondence Naeem Sultan Ali, MBBS, Department of \\ Otorhinolaryngology and Head Neck Surgery, The Aga Khan Hospital, \\ Barack Obama Avenue, P.O. Box 2289, Dar Es Salaam, Tanzania, United \\ Republic of Tanzania (e-mail: naeem.sultanali@gmail.com).
}

Int Arch Otorhinolaryngol 2015;19:200-204.

\begin{abstract}
Introduction Although venous thromboembolism (VTE) is seen with morbidity and mortality in various surgical specialties, scarce data are available in the head and neck surgery domain.

Objective We aim to determine the incidence of VTE in patients receiving surgery for head and neck cancer.

Methods Four hundred thirteen patients who underwent head and neck surgery procedures between 2005 and 2013 were reviewed retrospectively. All patients with head and neck surgery had received thromboprophylaxis (i.e., compression stockings and subcutaneous heparin). Patient demographics, operating time, and length of hospital stay were analyzed. The incidence of symptomatic deep venous thrombosis (DVT) and pulmonary embolism (PE) during the initial postoperative hospitalization was assessed.

Results Twelve patients were identified who developed VTE. Three patients developed DVT, and nine developed PE. The incidence of DVT and PE was 0.72 and $2.17 \%$, respectively. Interestingly, all of these patients had undergone excision of extensive

\section{Keywords}

- venous thromboembolism

- deep venous thrombosis

- pulmonary embolism

- thromboprophylaxis head and neck cancers accompanied by a reconstructive procedure. Patients who developed PE had a longer hospital stay compared with those who only had DVT. There were overall three mortalities in the nine patients who developed PE.

Conclusion Although VTE has a low incidence, it is a known complication of extensive head and neck surgeries with life-threatening outcomes. We recommend early mobilization and physiotherapy with the possible aid from appropriate mechanical and pharmacologic thromboprophylaxis.
\end{abstract}

\section{Introduction}

Venous thromboembolism (VTE), which includes deep venous thrombosis (DVT) and its sequelae pulmonary embolism
$(\mathrm{PE})$, are the leading causes of morbidity and mortality following surgical procedures. The incidence of DVT varies from 10 to $70 \%$ in inpatients. ${ }^{1}$ Death from DVT is attributed to massive PE, which causes as many as 300,000 deaths annually received

December 4, 2014

accepted

February 23, 2015

published online

March 27, 2015
DOI http://dx.doi.org/

10.1055/s-0035-1549153. ISSN 1809-9777.
Copyright $(2015$ by Thieme Publicações License terms

Ltda, Rio de Janeiro, Brazil $(\circledast) \Theta \Theta$ 
in the United States. ${ }^{2}$ Hospitalized patients are particularly at high risk, and PE is one of the most common preventable causes of hospital deaths. ${ }^{3}$ In cancer patients, the rates of recurrent VTE are at least 3 times that of patients without cancer. ${ }^{4,5}$ Although numerous effective methods are available for reducing and even preventing DVT and PE, studies have shown that only 21 to $35 \%$ of the surgeons take appropriate prophylactics steps to prevent DVT and PE for their patients. ${ }^{6,7}$

Patients with head and neck cancer usually undergo comprehensive resection and reconstruction and frequently exhibit many of the major risk factors for DVT and PE. These risk factors include advanced age, obesity, dyslipidemia, immobility because of a prolonged surgical procedure or extended hospital stay, and addiction like smoking and alcohol. ${ }^{1}$ Malignant disease itself can predispose to a hypercoagulable state secondary to polycythemia vera. ${ }^{8-10}$ The issue of DVT and PE has received little attention in otolaryngology and head and neck surgery literature, and limited data are available about the incidence of VTE. Very few studies have evaluated the incidence of DVT and PE in head and neck surgery. Incidences of 0.6 and $0.4 \%$ for DVT and PE, respectively, have been reported for patients having head and neck surgery, and head and neck cancer, old age, and lack of DVT prophylaxis were identified as independent risk factors. ${ }^{11}$

Factors such as low socioeconomic condition, illiteracy, and lack of resources pose a profound impact on good-quality patient care in third-world countries like Pakistan. As there is no report or study conducted on this issue in our part of world, our knowledge of the true incidence and contributing risk factors is limited in the field of otolaryngology. The purpose of this study was to determine the overall incidence of DVT and PE and to identify specific risk factors.

\section{Materials and Methods}

This was a retrospective review of all head and neck oncologic operations between 2005 and 2013. We identified and included all those inpatients who underwent head and neck procedures and developed either DVT, PE, or both as postoperative complications based on International Classification of Diseases9 and -10 coding system. Patients received subcutaneously low-molecular-weight heparin (LMWH) as prophylactic anticoagulation (5,000 $\mathrm{U}$ ) along with Tedd stockings an hour before procedure. Patient demographics including age, sex, weight, operating time, and length of hospital stay were analyzed. Other variables like obesity, hyperlipidemia, prior radiation, and previous head and neck surgeries were recorded. We risk stratified our patients with VTE based on a protocol for the incidence of VTE ( - Table $\mathbf{1}$ ). ${ }^{1}{ }^{12}$ Duration of surgical procedure was recorded from the time of skin incision till closure of skin. Only those cases using either pedicled or free flaps were considered as reconstruction. The incidence of symptomatic DVT and PE during the initial postoperative hospitalization was calculated. Patients were not routinely screened with biochemical or imaging studies; only patients with symptomatic DVT or $\mathrm{PE}$ (e.g., lower extremity pain or swelling, shortness of breath, chest pain, tachycardia, fever, etc.) were evaluated accordingly.
Table 1 Venous thromboembolism risk stratification

\begin{tabular}{|l|l|}
\hline Risks & Patient stratification \\
\hline Low & $\begin{array}{l}\text { Minor surgery in patients } \\
\text { age }<40 \mathrm{y}\end{array}$ \\
\hline Moderate & $\begin{array}{l}\text { Minor surgery in patients with } \\
\text { other risks }{ }^{\mathrm{a}} \text { or surgery in patients } \\
\text { aged } 40-60 \text { y without other risks }\end{array}$ \\
\hline High & Age $>60$ y or $40-60$ y with other risks \\
\hline Highest & Multiple risk factors \\
\hline
\end{tabular}

${ }^{a}$ Risks include surgery, trauma, immobility, malignancy, cancer therapy older age, pregnancy, medical illness, cardiac or pulmonary failure, obesity, smoking, coagulopathy, among others.

The diagnosis of DVT was confirmed by venous Doppler ultrasonography, whereas the diagnosis of PE was confirmed by a spiral computed tomographic scan of the chest.

A $t$ test was used for comparison of means of variables like age and length of surgery, Fisher exact test for gender and reconstruction, and Mann Whitney $U$ test for weight. A $p$ value of $<0.05$ was considered significant. Statistical analysis was performed using SPSS for Windows, version 16 (SPSS Inc., Chicago, Illinois, United States).

\section{Results}

A total of 413 head and neck procedures were performed at our institution. The mean age of these patients was 47 years ( \pm 8.29 ; range, 33 to 73 ). There were 265 men $(64.2 \%$ ) and 148 women (35.8\%).

Out of 413 patients, only 12 developed VTE (i.e., either DVT or PE). Reconstruction was performed in 194 patients and interestingly, all these 12 patients had undergone head and neck reconstruction. Three patients developed DVT, for an incidence of $0.72 \%$, and nine developed $\mathrm{PE}$, for an incidence of $2.17 \%$ (-Table 2).

Eight patients who developed VTE had stage IV disease (66\%), and the rest were stage III. Of the 12 who developed VTE, 9 were men (75\%) and 3 were women (25\%). In patients who had VTE, the mean age was 55.33 years, and those without VTE had mean age of 47.52 years, which was significant ( - Table 3 ). Similarly, mean length of surgery was 10.83 hours for patients who developed VTE and only 6.92 hours for others, which was also statistically significant. The mean weight of patients with VTE was $63.90 \mathrm{~kg}$, a statistically significant difference compared with patients

Table 2 Incidence of DVT and PE in head and neck cancer surgery patients

\begin{tabular}{|l|l|}
\hline Total no. of patients & 413 \\
\hline DVT $(n)$ & 3 \\
\hline DVT incidence (\%) & 0.72 \\
\hline PE $(n)$ & 9 \\
\hline PE incidence (\%) & 2.17 \\
\hline
\end{tabular}

Abbreviations: DVT, deep venous thrombosis; PE, pulmonary embolism. 
Table 3 Statistical analysis of patients with VTE

\begin{tabular}{|l|l|l|l|}
\hline Variables & $\begin{array}{l}\text { Patients } \\
\text { with } \\
\text { VTE }(\boldsymbol{n}=\mathbf{1 2})\end{array}$ & $\begin{array}{l}\text { Patients } \\
\text { without } \\
\text { VTE }(\boldsymbol{n}=\mathbf{4 0 1})\end{array}$ & $p$ Value \\
\hline Mean age (y) & 55.33 & 47.52 & 0.001 \\
\hline $\begin{array}{l}\text { Mean length } \\
\text { of surgery (h) }\end{array}$ & 10.83 & 6.92 & $<0.001$ \\
\hline $\begin{array}{l}\text { Sex } \\
\text { Male } \\
\text { Female }\end{array}$ & 9 & 256 & 0.5 \\
\hline $\begin{array}{l}\text { Reconstruction } \\
\text { Yes } \\
\text { No }\end{array}$ & 12 & 145 & $<0.001$ \\
\hline $\begin{array}{l}\text { Mean } \\
\text { weight (kg) }\end{array}$ & 0 & 182 & 0.041 \\
\hline
\end{tabular}

Abbreviation: VTE, venous thromboembolism.

without VTE $(55.32 \mathrm{~kg})$. Day 4 was the mean postoperative day of presentation of VTE. Day 3 was the average postoperative day of mobilization. The mean length of hospital stay for patients with DVT was 9.7 days; however, for patients with $\mathrm{PE}$, it was 20.9 days.

Nine of 12 patients had either hypertension or diabetes mellitus or both but none of them were obese or hyperlipidemic. Three patients had no comorbidity. None of our patients had previous history of thrombosis or other cardiovascular diseases. Of the 9 patients who had PE, there were 3 in-house deaths most likely secondary to myocardial infarction or arrhythmias. In all cases, symptomatic DVT or PE was initially treated with intravenous heparin infusion, which was later replaced by warfarin.

Two of our patients fell into the moderate-risk group and remaining 10 patients fell into the high-risk group. All 12 patients received thromboprophylaxis including the 3 who died. The prophylaxis used was heparin $(5,000 \mathrm{U} / \mathrm{h})$ before surgery and twice daily postoperatively.

\section{Discussion}

The overall incidence of DVT and PE in our review of patients having head and neck surgery at our tertiary care hospital was low compared with that of other surgical specialities. In patients having abdominal surgery and receiving heparin prophylaxis, the reported frequency of DVT and PE is 9 and $1.3 \%$, respectively. ${ }^{8}$ However, in patients not receiving thromboprophylaxis, the estimated incidence is 15 to $30 \%$ for $\mathrm{DVT}^{1,13}$ and from 0.5 to $1.6 \%$ for PE. ${ }^{1,11}$ Among vascular surgery, the reported incidence of VTE was 2.5 to $2.9 \%{ }^{12}$ The incidence of DVT in gynecologic surgery ranges from 10 to $40 \%$ without routine use of thromboprophylaxis. ${ }^{14,15} \mathrm{In}$ plastic surgery, the incidence of VTE after abdominoplasty has been reported as $1.4 \%,{ }^{16}$ and after rhytidectomy, the incidence of VTE was $0.35 \% .{ }^{17}$ Orthopedic surgery is known to have a postoperative incidence of DVT that exceed $50 \%$ and rate of PE as high as $12.9 \%{ }^{13,18}$

In a study by Moreano et al, ${ }^{11} 300$ patients had head and neck reconstruction and none of them developed DVT or PE postoperatively in contrast to our study where we had 12 patients with VTE. In our study, there were 194 head and neck reconstruction surgeries, resulting in 3 cases of symptomatic DVT $(0.72 \%)$ and 9 cases of PE (2.17\%). Chen and colleagues found a fourfold increase in incidence of VTE in patient undergoing head and neck reconstruction compared with those of non-head and neck reconstruction. ${ }^{19}$ Our rate of $0.72 \%$ for DVT is slightly higher than that reported by Innis and Anderson. ${ }^{20}$ A reason often cited for these higher rates of thromboembolic events in patients undergoing head and neck surgical procedure is that they are usually elderly patients with more serious comorbid conditions, which ultimately increases the likely hood of the development of DVT and PE. Over $70 \%$ of our patients with VTE were above 50 years, and only one patient was younger than 40 years. It was of interest that all our patients who developed VTE issues were those who had head and neck reconstruction done with no history of any previous treatments. Although the rate of internal jugular vein thrombosis after neck dissection ranges from 15 to $33 \%, 21,22$ in our study we have not done postoperative computed tomography, high-resolution ultrasound, or color-flow Doppler study, and we cannot comment on internal jugular or subclavian vein thrombosis.

By looking at our length of operating time in the VTE group, surgery lasted for more than 10 hours, which was statistically significant. Moreano and colleagues found that the majority of their patients with VTE had operations lasting over 2 hours. ${ }^{11}$ We also found statistical significance in terms of weight in patients with VTE, similar to Moreano et al, who found that almost $47 \%$ of their patients were above $80 \mathrm{~kg} .{ }^{11}$ When considering these results all together, it seems that patients who were older and who underwent longer head and neck cancer surgery are at greater risk of developing VTE. These finding are consistent with current recommended guidelines for VTE prophylaxis that emphasize age and length of operating time as risk factors. ${ }^{1,11,23}$

As we included only patients who were symptomatic (lower extremity pain or swelling, shortness of breath, chest pain, tachycardia) and asymptomatic patients were not routinely screened with biochemical or imaging studies, it is possible that we have missed many patients and the actual incidence of VTE could be higher. When comparing the morbidity and mortality of our patients with VTE, we found that patients who developed DVT had a shorter mean hospital stay than that of patients with PE (9.7 days for DVT and 20.9 days for PE). Similar finding were also reported by Lee and colleagues $^{24}$; however, their patients with PE stayed for over 36 days compared with our stay of almost 21 days. When comparing our results, we found that our incidence of PE was much higher than the other studies (- Table 4).

One important factor that seriously contributes to lack of mobilization and disuse of Tedd stockings is patient compliance. Despite constant counseling, a majority of our patients have a misconception that early mobilization will seriously hinder the healing process. The intensely hot and humid environment is an additional factor and discourages patients from moving around as well as from using Tedd stockings. 
Table 4 Literature review of Incidence of VTE in head and neck surgery patients

\begin{tabular}{|c|c|c|c|}
\hline Study & $\begin{array}{l}\text { No. of } \\
\text { patients }\end{array}$ & $\begin{array}{l}\text { Incidence of } \\
\text { DVT (\%) }\end{array}$ & $\begin{array}{l}\text { Incidence of } \\
\text { PE (\%) }\end{array}$ \\
\hline Moreano et al $^{11}$ & 3,463 & 0.6 & 0.4 \\
\hline Lee et $\mathrm{al}^{24}$ & 3,647 & 0.2 & 0.1 \\
\hline Innis ${ }^{20}$ & 542 & 0.6 & 0 \\
\hline Chen et al $^{19}$ & 1,591 & 0.31 & 0.44 \\
\hline Our study & 413 & 0.72 & 2.17 \\
\hline
\end{tabular}

Abbreviations: DVT, deep venous thrombosis; PE, pulmonary embolism; VTE, venous thromboembolism.

The literature clearly describes the risk factors for patients developing VTE and also that the use of thromboprophylaxis decreases the rate of DVT and PE.,2,25 There are specific recommendations for other surgical specialities, but unfortunately not for otolaryngology specifically. Understanding guidelines and recommendations from other specialities will help us to make more appropriate decisions for our patients.

For patients with cancer who are undergoing major surgery, the American College of Chest Physicians recommendations include routine thromboprophylaxis with LMWH 10,000 to $15,000 \mathrm{IU} / \mathrm{d}$. For patients with cancer with additional risk for VTE, the recommendation is to use LMWH in combination with mechanical methods such as sequential compression devices. ${ }^{26}$ Hence, modalities for thromboprophylaxis are both mechanical and pharmacologic. Mechanical prophylaxis methods such as elastic (Tedd) stockings, intermittent pneumatic compression devices, and venous foot pump have been demonstrated to be effective and safe. These devices counteract stasis, one of the three aspects of Virchow's triad. ${ }^{1}$ Pharmacologic options for thromboprophylaxis include unfractionated heparin, LMWH, fondaparinux, and vitamin $\mathrm{K}$ antagonists. ${ }^{1,26-28}$ Warfarin is not routinely used for DVT prevention in our setup. It is mainly used once DVT is established.

According to risk stratification system, a majority of patients with head and neck cancer fell into high-risk group (e.g., elderly patients with cancer and multiple comorbidities) and should be dealt with using aggressive thromboprophylaxis. ${ }^{1,12}$ When compared with no prophylaxis, unfractionated heparin and LMWH have been shown to reduce VTE risk by at least $60 \%{ }^{8,12,29}$ Despite the mechanical (Tedd stocking) and pharmacologic therapy (heparin 5,000 U twice daily), our patients developed VTE. Pneumatic devices that help to reduce the intraoperative risks of DVT are unfortunately not freely available at our institution. Meta-analysis has shown that pneumatic compression devices also decrease DVT in patients undergoing surgical procedures by over $60 \%{ }^{18}$ Moreano et al showed that the use of a pneumatic compression device decreases the likelihood of a thromboembolic event by one fourth. ${ }^{11}$

To reduce VTE, we recommend mobilizing patients as early as the second postoperative day. Moreover, intermittent leg exercises, early mobilization, and educating the patients and nursing staff will further decrease the rate of VTE.
In summary, challenges to good patient care in Pakistan include our cultural factors of disbelief, environmental issues of oppressive heat, and lack of resources like intraoperative pneumatic devices.

\section{Conclusion}

Based on our data, we concur that the rate of symptomatic VTE in patients with head and neck cancer was relatively low as compared with reported rates of other surgical specialties and in general otolaryngology, but it was higher when compared with other head and neck reconstructive studies.

Because VTE is potentially a detrimental complication in patients with cancer, we would recommend that all patients with head and neck cancer surgery should be mobilized very early, and unless otherwise contraindicated, they should be dealt with appropriate mechanical and pharmacologic thromboprophylaxis.

\section{References}

1 Geerts WH, Pineo GF, Heit JA, et al. Prevention of venous thromboembolism: the Seventh ACCP Conference on Antithrombotic and Thrombolytic Therapy. Chest 2004;126(3, Suppl):338S-400S

2 Tapson VF. Acute pulmonary embolism. N Engl J Med 2008; 358(10):1037-1052

3 Bergqvist D, Lindblad B. A 30-year survey of pulmonary embolism verified at autopsy: an analysis of 1274 surgical patients. Br J Surg 1985;72(2):105-108

4 Levine MN, Lee AY. Treatment of venous thrombosis in the cancer patient. Acta Haematol 2001;106(1-2):81-87

5 Levitan N, Dowlati A, Remick SC, et al. Rates of initial and recurrent thromboembolic disease among patients with malignancy versus those without malignancy. Risk analysis using Medicare claims data. Medicine (Baltimore) 1999;78(5):285-291

6 Anderson FA Jr, Wheeler HB, Goldberg RJ, Hosmer DW, Forcier A, Patwardhan NA. Physician practices in the prevention of venous thromboembolism. Ann Intern Med 1991;115(8):591-595

7 Conti S, Daschbach M. Venous thromboembolism prophylaxis: a survey of its use in the United States. Arch Surg 1982;117(8): 1036-1040

8 Agnelli G. Prevention of venous thromboembolism in surgical patients. Circulation 2004;110(24, Suppl 1):IV4-IV12

9 Flordal PA, Bergqvist D, Ljungström KG, Törngren S; Fragmin Multicentre Study Group. Clinical relevance of the fibrinogen uptake test in patients undergoing elective general abdominal surgery-relation to major thromboembolism and mortality. Thromb Res 1995;80(6):491-497

10 Ah-See KW, Kerr J, Sim DW. Prophylaxis for venous thromboembolism in head and neck surgery: the practice of otolaryngologists. J Laryngol Otol 1997;111(9):845-849

11 Moreano EH, Hutchison JL, McCulloch TM, Graham SM, Funk GF, Hoffman HT. Incidence of deep venous thrombosis and pulmonary embolism in otolaryngology-head and neck surgery. Otolaryngol Head Neck Surg 1998;118(6):777-784

12 Geerts WH, Heit JA, Clagett GP, et al. Prevention of venous thromboembolism. Chest 2001;119(1, Suppl):132S-175S

13 Mismetti P, Laporte S, Darmon JY, Buchmüller A, Decousus H. Meta-analysis of low molecular weight heparin in the prevention of venous thromboembolism in general surgery. Br J Surg 2001; 88(7):913-930

14 Schreiner WE. [Perioperative prevention of thromboembolism in gynecology]. Arch Gynecol 1986;239(3-4):137-143 
15 Clarke-Pearson DL, Dodge RK, Synan I, McClelland RC, Maxwell GL. Venous thromboembolism prophylaxis: patients at high risk to fail intermittent pneumatic compression. Obstet Gynecol 2003; 101(1):157-163

16 van Uchelen JH, Werker PM, Kon M. Complications of abdominoplasty in 86 patients. Plast Reconstr Surg 2001;107(7):1869-1873

17 Reinisch JF, Bresnick SD, Walker JW, Rosso RF. Deep venous thrombosis and pulmonary embolus after face lift: a study of incidence and prophylaxis. Plast Reconstr Surg 2001;107(6): 1570-1575, discussion 1576-1577

18 Clagett GP, Anderson FA Jr, Levine MN, Salzman EW, Wheeler HB. Prevention of venous thromboembolism. Chest 1992;102(4, Suppl):391S-407S

19 Chen CM, Disa JJ, Cordeiro PG, Pusic AL, McCarthy CM, Mehrara BJ. The incidence of venous thromboembolism after oncologic head and neck reconstruction. Ann Plast Surg 2008;60(5):476-479

20 Innis WP, Anderson TD. Deep venous thrombosis and pulmonary embolism in otolaryngologic patients. Am J Otolaryngol 2009; 30(4):230-233

21 Fisher CB, Mattox DE, Zinreich JS. Patency of the internal jugular vein after functional neck dissection. Laryngoscope 1988;98(9):923-927

22 Leontsinis TG, Currie AR, Mannell A. Internal jugular vein thrombosis following functional neck dissection. Laryngoscope 1995; 105(2):169-174

23 Haas S. Recommendations for prophylaxis of venous thromboembolism: International Consensus and the American College of
Chest Physicians Fifth Consensus Conference on antithrombotic therapy. Curr Opin Pulm Med 2000;6(4):314-320

24 Lee J, Alexander A, Higgins K, Geerts W. The Sunnybrook experience: review of deep vein thrombosis and pulmonary embolism in otolaryngology. J Otolaryngol Head Neck Surg 2008;37(4): 547-551

25 Heit JA. The Epidemiology of Venous Thromboembolism in the Community. Arterioscler Thromb Vasc Biol 2008;28(03):370-372

26 Gould MK, Garcia DA, Wren SM, et al. Prevention of VTE in nonorthopedic surgical patients: Antithrombotic Therapy and Prevention of Thrombosis, 9th ed: American College of Chest Physicians Evidence-Based Clinical Practice Guidelines. Chest 2012;141(2 Suppl):e227S-277S

27 Samama MM, Cohen AT, Darmon JY, et al; Prophylaxis in Medical Patients with Enoxaparin Study Group. A comparison of enoxaparin with placebo for the prevention of venous thromboembolism in acutely ill medical patients. N Engl J Med 1999;341(11):793-800

28 Cohen AT, Davidson BL, Gallus AS, et al; ARTEMIS Investigators. Efficacy and safety of fondaparinux for the prevention of venous thromboembolism in older acute medical patients: randomised placebo controlled trial. BMJ 2006;332(7537):325-329

29 Collins R, Scrimgeour A, Yusuf S, Peto R. Reduction in fatal pulmonary embolism and venous thrombosis by perioperative administration of subcutaneous heparin. Overview of results of randomized trials in general, orthopedic, and urologic surgery. N Engl J Med 1988;318(18):1162-1173 